\title{
The Protective Effect of the Mediterranean Diet: Focus on Cancer and Cardiovascular Risk
}

\author{
Ernest K.J. Pauwels \\ University of Pisa Medical School, Pisa, Italy
}

\author{
Key Words \\ Mediterranean diet $\cdot$ Anti-inflammatory agent • \\ Antioxidant $\cdot$ Omega-3 $\cdot$ Olive oil $\cdot$ Red wine $\cdot$ Cancer . \\ Cardiovascular disease
}

\begin{abstract}
The lower occurrence of cancer and cardiovascular disease in the population around the Mediterranean basin has been linked to the dietary habits of the region. Indeed, this socalled Mediterranean diet is essentially different from the diets consumed in Western and Northern European countries and is rich in nuts, fruits, vegetables, legumes, whole-wheat bread, fish, and olive oil, with moderate amounts of red wine, which is mainly consumed during meals. Although a variety of cultural and religious traditions exist among the peoples of the Mediterranean area, olive oil, fish, and red wine hold a traditional and central position in the culinary routines of the region. The components of the diet contain an ample source of molecules with antioxidant and anti-inflammatory actions, among which omega-3 fatty acids, oleic acid, and phenolic compounds hold a prominent place. This review will summarize the results of important epidemiological studies that have investigated the protective effect of fish and olive oil on the risk of breast, prostate, and colorectal cancer and of wine on the risk of cardiovascular disease. The
\end{abstract}

present review also aims to elucidate the various mechanisms by which various dietary components exhibit their beneficial action. In this respect, emphasis will be placed on the properties of omega- 3 fatty acids from fish, oleic acid from olive oil, and phenolic compounds from olive oil and red wine.

Copyright @ 2011 S. Karger AG, Basel

\section{Introduction}

More than in other regions, the population of the area around the Mediterranean basin adheres to the so-called Mediterranean diet, which is rich in nuts, fruits, vegetables, legumes, whole-wheat bread, fish, and olive oil. Alcohol, mostly in the form of red wine, is consumed with meals in moderate amounts. These ingredients make this diet essentially different from the diets of Western and Northern European countries. Thus, the relatively lower occurrence of chronic diseases in this region, such as cancer, diabetes, obesity, and cardiovascular disease, has been linked to dietary habits. Recent data from a general study of the Greek population, with a sample size of 25,623 participants and a median follow-up of 7.9 years, has provided evidence that adherence to the traditional Greek Mediterranean diet is associated with a $12 \%$ reduc-

\section{KARGER \\ Fax +4161306 1234 \\ E-Mail karger@karger.ch}

www.karger.com
() 2011 S. Karger AG, Basel

1011-7571/11/0202-0103\$38.00/0

Accessible online at:

www.karger.com/mpp
Prof. Dr. Ernest K.J. Pauwel

Via di San Gennaro 79 B

IT-55010 Cappanori (Italy)

Tel. +390583978080

E-Mail ernestpauwels@gmail.com 
tion in overall cancer incidence [1]. Analyzing the impact of a particulate dietary variable on cancer development, the highest reduction in cancer incidence was observed for the ratio of monosaturated to saturated lipids, vegetables, and olive oil (respective hazard ratios of 0.91, 0.96, and 0.97).

These interesting data provide further support to the pioneering Seven Countries Study conducted by Keys et al. [2], which was an intercohort study carried out in Finland, Italy, Greece, the former Yugoslavia, the Netherlands, Japan, and the USA. This investigation found a relatively low incidence of cardiovascular disease and cancer in the Mediterranean cohorts. Although the Mediterranean area has different cultural and religious traditions, for many centuries olive oil, fish and (red) wine have held a central and appreciated culinary position. Olive oil, especially virgin olive oil, and fish are the major sources of fat which - together with the ingredients of red wine - give rise to antioxidant and anti-inflammatory actions presumably contributing to the prevention of chronic diseases.

This review will summarize the results of important epidemiological studies that have investigated the protective effect of fish and olive oil on the risk of breast, prostate, and colorectal cancer and of wine on the risk of cardiovascular disease. The scope of this paper is to provide a survey of the relevant knowledge of the effect of the Mediterranean diet on these illnesses, which are among the most prevalent disabling and fatal diseases. The present review also aims to elucidate the various mechanisms by which many dietary components exhibit their beneficial action. In this respect, emphasis will be put on the properties of omega-3 fatty acids from fish, oleic acid from olive oil, and phenolic compounds from olive oil and red wine.

\section{Data Sources}

A search of PubMed, Embase, and Web of Science was conducted using the keywords Mediterranean diet, antiinflammatory agent, antioxidant, omega-3, olive oil, red wine, cancer, and cardiovascular disease, in relevant combinations. Literature, restricted to articles written in English, was retrieved from the full history of publications up to February 1, 2010. Full articles were retrieved by the selection of electronically obtained summaries. An effort was made to include only the more recent of multiple articles on the same subject in the list of references published over the last decennium.

\section{Protective Mechanisms of Omega-3 Polyunsaturated Fatty Acids against Cancer Risk}

Omega- 6 and omega-3 polyunsaturated fatty acids (PUFAs), also named n-6 and n-3 PUFAs after the position of the final double bond from the end of the methyl group position, cannot be synthesized de novo by mammalian cells. Therefore, the presence of these acids is highly dependent on dietary intake, and members of the n- 6 and n-3 families are often called 'essential fatty acids' [3]. The precursor of the $n-6$ family is linoleic acid (LA), and the precursor of the $n-3$ family is alpha-linolenic acid (ALA). LA can be obtained from eggs, poultry, vegetable oils, and whole-grain bread, and ALA from flaxseed, linseed, soy oils, walnuts, and leafy green vegetables. The metabolism of dietary LA and ALA requires the same set of delta- 6 and delta- 5 desaturases and elongases, although the $\mathrm{n}-3$ family members are the preferred substrates. The n- 6 metabolite $\gamma$-linolenic acid and the n-3 metabolites, i.e. eicosapentaenoic acid (EPA) and docosahexaenoic acid (DHA) and their biochemical derivatives called eicosanoids, are biologically active agents with anti-inflammatory effects; these compounds can be taken directly as dietary components to bypass the slow enzymatic processes in the n- 6 and n-3 families.

Eicosanoids are hormone-like lipids with a chain length of 20 carbon atoms. An important eicosanoid member of the $n-6$ family, arachidonic acid (AA), the major n-6 PUFA in cell membranes, is metabolized to the 2 -series of prostanoids and the 4-series of leukotrienes. These AA-derived eicosanoids have a proinflammatory action. Suppression of the biosynthesis of these proinflammatory molecules can be achieved by a higher intake of n-3 PUFAs, resulting in an increased presence in the cell membrane at the expense of the AA concentration and its metabolites. In addition, an increased level of EPA from n-3 precursors or dietary supplements gives rise to the formation of anti-inflammatory lipid mediators, including resolvins, protectins, and maresins, known to suppress the immune response [4]. Although inflammation is part of the host defense system, sustained inflammation due to environmental and biological triggers may lead to the overproduction of reactive species, causing DNA damage and modification as well as the activation of oncogenes and the inactivation of repair and tumor suppressor genes.

Apart from the above described mechanism, n-3 PUFAs can regulate transcription factors serving as endogenous ligands. For instance EPA and DHA, ligands of the peroxisome proliferator-activated receptors, can ex- 
hibit antiproliferative effects in colon cancer cells [5], induce apoptosis [6], and have an anti-inflammatory action [7]. Likewise, activation of the nuclear transcription factor-kappa B (NF- $\mathrm{BB})$, which is involved in cell proliferation and adhesion processes, can be decreased by $n-3$ PUFAs [8]. Furthermore, n-3 PUFAs alter the basic properties of the architecture and biochemical makeup of the cell membrane, influencing the process of signal transduction and inducing apoptotic cell death in cancer cells [9]. Also, PUFAs of the $n-3$ series but not the $n-6$ series can diminish estrogen formation and consequently the estrogen-induced growth of breast cancer cells, for example [10]. An important feature of n-3 PUFAs is the modification of the inflammatory response generated by free radicals and reactive oxygen and nitrogen species within the cell. Interesting experiments by Yaqoob and Calder [11] and Kenar et al. [12] have demonstrated that n-3 fatty acid supplementation suppresses inflammation and diminishes oxidative stress.

\section{Protective Mechanisms of Olive Oil Components against Cancer Risk}

Olive oil-associated mechanisms presumably contributing to good health primarily entail anti-inflammatory and antioxidant properties $[13,14]$. The phenolic compounds present in olive oil may interact with the inflammatory cascade via their antioxidant action. This interaction is primarily related to their ability to scavenge free radicals, thus preventing cellular injury [15]. In addition, a relatively high concentration of oleic acid, the main monounsaturated fatty acid (MUFA) of olive oil in the membrane phospholipids, makes the cell less susceptible to oxidation by reducing the formation of proinflammatory molecules [16]. These chemoprotective properties may translate into a number of protective mechanisms beneficial to health, including protection against viral infection and cancer development, as well as cardiovascular protection.

\section{Protective Mechanisms of Red Wine against Cardiovascular Disease Risk}

Red wine contains a variety of phenolic compounds which exert anti-inflammatory, antioxidant, and antiatherogenic actions [17]. Although the consumption of drinks containing alcohol (ethanol) has been linked to a lower total mortality [18], the bulk of experimental stud- ies demonstrate the 'beyond-alcohol effect' of red wine consumption. Among the phenolic compounds in red wine, resveratrol (3,4,5-trihydroxystilbene) takes a prominent place. This antioxidant is a phytochemical predominantly present in red wine that originates from the skin and seeds of grapes. In contrast, white wine contains a lower concentration of this molecule as its production process uses fermentation after the removal of the grape seeds and skin. Resveratrol serves as an antifungal and antibacterial agent to protect the grape against its environment. This compound has been most extensively studied in relation to its cardiovascular health benefits attributed to beneficial actions on LDL oxidation, thrombogenecity, ischemia, and vascular tone [19]. Its antioxidant activity has been attributed to the inhibition of TNF- $\alpha$-activated NF- $\kappa \mathrm{B}$ signaling, which leads to a reduced biosynthesis of proinflammatory prostaglandins and a reduced activity of cyclooxygenase-2 [20]. Other substances of interest in red wine include procyanidins and proanthocyanidins. Corder et al. [21] have shown that these compounds improve vasodilatory activity by reducing the production of the vasoconstrictor, i.e. endothelin. However, red wine is a complex fluid in which more than 500 compounds have been found, only a few of which have been explored [22].

\section{Epidemiological Studies on Omega-3 Fatty Acids and Cancer Risk}

\section{Effects on the Risk of Breast Cancer}

A systematic review published between 1966 and 2005 by MacLean et al. [23] in 2006 identified 8 studies from 6 different cohorts that evaluated the effects of omega-3 fatty acids on breast cancer risk. The authors concluded that this risk was not clearly related to the consumption of EPA and DHA. The studies that were included in their review estimated fatty acid intake on the basis of questionnaires. More recently, various epidemiological studies have drawn a different picture. The ones that relate the levels of EPA and DHA in erythrocyte membranes demonstrate a significant inverse association between breast cancer risk and EPA concentration, but not DHA concentration $(\mathrm{p}<0.0006)[24,25]$. This important information is based on the new concept of fatty acid assessment and casts doubt on the results of previously published studies on the same subject, although the questionnaire-based study by Kim et al. [26] published in 2009 also found a significant reduction in breast cancer risk. Based on a 103-item food questionnaire, these researchers applied a 
multivariate logistic regression model and found a reduced risk in both premenopausal $(\mathrm{p}<0.001)$ and postmenopausal women $(p=0.005)$. These beneficial results were obtained in those who had a high consumption of fish. Postmenopausal women consuming more than $0.1 \mathrm{~g}$ of EPA and $0.2 \mathrm{~g}$ of DHA from fish per day, respectively, showed a 62 and $68 \%$ decrease in breast cancer risk compared to the reference group, which consumed less than $0.01 \mathrm{~g}$ of EPA and $0.04 \mathrm{~g}$ of DHA per day.

\section{Effects on the Risk of Prostate Cancer}

A large prospective cohort study by Leitzmann et al. [27] published in 2004, comprising 47,866 US health professionals with a follow-up of 14 years, found that men with a high consumption of fish had a lower prostate cancer risk. This finding is in contrast with the results obtained in an 18-year follow-up study in 40,230 US male health professionals by Virtanen et al. [28] published in 2008 . With the inclusion of 4,690 cancer cases, the latter study had enough power to detect any change in risk in relation to fish intake. The authors mention that a small health benefit might be counterbalanced by cancer-promoting fish contaminants such as dioxins and polychlorinated biphenyls [29]. Both the study by Leitzmann et al. [27] and that by Virtanen et al. [28] were carried out using dietary questionnaires on subjects that were health care professionals and who would be more likely than any other group to provide reliable data on dietary intake. Another recent questionnaire-based case-control study investigated the dietary habits of 386 cancer patients and concluded that a fish diet was associated with a 2 -fold reduction in prostate cancer risk $(\mathrm{p}=0.017)$, whereas meat diets appeared to be associated with a 3 -fold increased risk of prostate cancer $(\mathrm{p}=0.027)$ [30].

As mentioned above, results based on membrane fatty acid assessment might provide new insight into this matter, but such studies are practically impossible to carry out on a large group of subjects. A study by Ritch et al. [31] of 24 cases of prostate cancer in Jamaica supports the association between dietary fatty acids and prostate cancer risk. In particular, these investigators found that n- 6 PUFAs stimulate prostate cancer progression while n-3 PUFAs inhibit it.

\section{Effects on the Risk of Colorectal Cancer}

A most interesting study by Norat et al. [32] reported on the incidence of colorectal cancer in relation to fish intake. This study prospectively followed 478,040 cancer-free men and women from 10 European countries between 1992 and 1998 with a mean follow-up of 4.8 years. During this questionnaire-based study 1,329 participants were diagnosed with colorectal cancer. The study showed that the disease and the consumption of red and processed meat are positively related $(\mathrm{p}=0.001)$, whereas the association with fish intake appeared to be inverse $(\mathrm{p}=0.003)$. Another large study, the ongoing Physicians Health Study which started in 1982, comprised 22,071 healthy male physicians. During a followup period of 22 years, 500 men had a confirmed diagnosis of colorectal cancer. Fish intake, and more specifically n-3 fatty acid intake, was inversely related to both colon and rectal cancer risk $(\mathrm{p}=0.01)$ [33]. These large studies were questionnaire-based and, to the best of our knowledge, only 1 human study relating the fatty acid composition in the erythrocyte membrane to colorectal cancer has been published; that study, by Kuriki et al. [34], showed a decreased risk of colorectal cancer in relation to the ratio between saturated and n-3 fatty acids $(\mathrm{p}<0.005)$.

\section{Epidemiological Studies on Olive Oil and Cancer Risk}

\section{Effects on the Risk of Breast Cancer}

A recent case-control study in 1,703 breast cancer patients and 2,045 controls performed in the San Francisco Bay Area showed that cooking with olive oil, which is rich in oleic acid, reduced the risk of breast cancer compared with hydrogenated fats (OR 1.58; 95\% CI 1.202.10) or with vegetable/corn oil, which is rich in linoleic acid (OR 1.30; 95\% CI 1.06-1.58) [35]. The so-called Potsdam (Germany) study was a prospective investigation of the effect of high-fat food choices on the incidence of breast cancer [36]. This study followed 15,351 female subjects over an average period of 6.0 years. The investigation concluded that the total dietary fat rather than specific fatty acids is associated with a 2 -fold increased risk of breast cancer (hazard ratio 2.00; 95\% CI 1.303.09), comparing extreme tertiles of the pattern score. The French component of the European Prospective Investigation into Cancer and Nutrition (EPIC) documented the MUFA intake in 19,934 women, 363 of whom developed breast cancer during an average follow-up of 7 years [37]. The intake of cis-MUFA (a group to which oleic acid belongs) appeared to be unrelated, whereas an increased risk was associated with increasing levels of trans-MUFA, the odds ratio being 1.75 (95\% CI 1.082.83), when comparing the highest quintile with the lowest. Interestingly, the large prospective EPIC study com- 
prising 319,826 women identified 7,119 women who developed breast cancer over a mean period of 8.8 years of follow-up. No significant association with total fat, MUFA, or PUFA could be determined, although a weak positive association between saturated fat intake and breast cancer risk in postmenopausal women who never used hormone therapy was found [38].

Concerning the phenolic constituents of olive oil, a high concentration of these antioxidants is associated with a protective effect on oxidative damage as reviewed by Fitó et al. [39]. A multicenter, double-blind, randomized, crossover controlled intervention trial in Southern, Central, and Northern European countries showed a reduction in DNA oxidation of $13 \%(p=0.008)$ for all types of olive oil consumed, although no association was found with the level of phenolics. How far these results translate into a reduced risk of breast cancer or any other cancer is uncertain and warrants further study [40].

\section{Effects on the Risk of Prostate Cancer}

The aforementioned EPIC study also investigated whether dietary fat might be a contributing factor in the etiology of prostate cancer. This objective was assessed in a multicenter study in 142,520 men. After a median follow-up of 8.7 years, prostate cancer was diagnosed in 2,727 men. Analysis of the data obtained by country-specific validated food questionnaires did not reveal an association between any type of dietary fat, including olive oil, and prostate cancer risk [41]. This outcome confirms the results of a previously published large prospective study in which no association between these 2 entities could be demonstrated [42].

\section{Effects on the Risk of Colorectal Cancer}

A large 7-year case-control study by Theodoratou et al. [43] on oleic acid and other fat consumption included 1,455 cases and 1,455 matched controls. The results showed no clear association between oleic acid intake and colorectal cancer risk as opposed to the inverse relationship found for omega-3 fatty acid intake. A differently designed study [44] of an ecological nature examined the national levels of dietary factors, with particular reference to olive oil. The researchers found that $76 \%$ of the intercountry variation in colorectal cancer was explained by 3 significant dietary factors in combination: meat, fish, and olive oil. Olive oil was negatively associated with cancer incidence, which was emphasized by Cicerale et al. [45] in an excellent review on olives, olive oil, and disease prevention.

The Protective Effect of the

Mediterranean Diet

\section{Epidemiological Studies on Red Wine and Cardiovascular Risk}

In 1979, St Leger et al. [46] reported that an inverse relationship existed between coronary heart disease (CHD) mortality and wine consumption in France. Subsequently, in 1992, Renaud and De Lorgeril [47] reported that the consumption of alcohol in France (20-30 mg/day) was associated with a reduction in the risk of CHD of at least $40 \%$. This is an interesting finding as the French diet is well-known for its high content of saturated fat, which is known to be associated with CHD. Recent WHOSIS data still show that France has the lowest percentage of death due to cardiovascular disease of all European countries (http://www.ehnheart.org).

\section{Studies on Alcohol}

An excellent paper by Di Castelnuovo et al. [48] reported a meta-analysis of 34 prospective studies up to December 2005. On the basis of a total of $1,015,835$ men and women and 94,533 deaths, they found that the lowest mortality occurred at $6 \mathrm{~g}$ of alcohol per day (RR 0.8; $95 \%$ CI $0.80-0.83$ ). Lower mortality was observed at up to 4 drinks per day for men and up to 2 drinks per day for women compared to abstinence. One of the studies included in this meta-analysis was conducted by Gaziano et al. [49], who investigated the cause of death of 89,299 male subjects recruited from the Physicians' Health Study over a period of 5.46 years. During that period, $3.6 \%$ of the subjects died; $45.1 \%$ of them succumbed due to cardiovascular disease (CVD). The investigation showed that a risk reduction in CVD mortality amounting to $32-47 \%$ occurred even at 'more than 2 drinks a day' although the maximum benefit was reached at 1 drink per day. This result is in accordance with a prospective study by Klatsky et al. [50] in a population of 128,934 adults over a period of 7 years. They revealed a relative risk of CHD of 0.7 (95\% CI 0.6-0.9), independent of the baseline risk for moderate alcohol drinkers (up to 2 drinks a day) compared to lifelong nondrinkers. The greatest reduction was observed in drinkers over 50 years of age. In contrast, individuals under 50 years of age consuming 6 or more drinks a day showed a relative risk of death from all causes of 1.9 (95\% CI 1.2-2.9) compared to lifelong nondrinkers. This increased risk was more evident in women than men. Apart from these studies, other cohort studies have consistently shown that moderate alcohol use is associated with a lower risk of CHD and CVD compared to heavy drinking or abstinence. Among the most recent articles are those by Snow et al.

Med Princ Pract 2011;20:103-111 
[51], Bazzano et al. [52], Saremi and Arora [53], and Foerster et al. [54].

\section{Studies on Wine}

Recent large epidemiological studies on cardiovascular health include those by Grønbaek et al. [55] (13,064 men and 11,459 women; follow-up about 10 years), Renaud et al. [56] (36,583 men; follow-up 13-21 years), and Klatsky et al. [57] (56,926 men and 72,008 women; followup 20 years or known death). From these studies, a conservative estimate on the reduced risk of cardiovascular mortality for moderate drinkers of red wine (1-3 glasses a day) amounts to 0.7 compared to nondrinkers.

An intriguing question is whether red wine has qualities beyond the 'alcohol effect'. Studies on flow-mediated arterial dilatation found a greater effect after drinking dealcoholized red wine than after drinking regular red wine $[58,59]$. Moreover, in a double-blind crossover study in 20 healthy volunteers, it appeared that endothelial dysfunction induced by cigarette smoking could be counterbalanced by the simultaneous consumption of dealcoholized red wine or regular red wine [60]. Indeed, a recent study showed that both red wine and dealcoholized red wine decrease plasma endothelin-1 levels, although the researchers could not determine a significant effect on coronary epicardial diameters or flow rate [61]. These human studies underscore the benefit of red wine beyond the known effect of alcohol. The polyphenols found in red wine, particularly resveratrol, are supposedly active on cardiovascular endpoints [62].

Another question is whether white wine could exert effects similar to those of red wine. The large prospective studies by Klatsky et al. [57] and Mukamal et al. [63] did not detect any influence of the type of wine as far as cardiovascular risk is concerned despite the 'bonus' effect of red wine, in which polyphenols are more abundant [64]. This is in agreement with the results of experimental investigations suggesting that white wine can provide cardioprotection similar to that afforded by red wine if it is rich in tyrosol and hydroxytyrosol [65]. It should be realized that the effect of wine consumption is difficult to evaluate epidemiologically. If food/drink questionnaires are used, it must be recognized that a certain degree of underreporting with regard to alcohol use in general undoubtedly plays a part in the analysis. Rather than using self-reported questionnaires, nutritional biomarkers would help to evaluate wine consumption. Zamora-Ros et al. [66] validated urinary resveratrol metabolites by liquid chromatography-mass spectrometry and concluded that they may be useful as biomarkers of wine intake in human investigations and epidemiological studies. From a pathophysiological point of view, the formation of atherosclerotic plaques in humans takes decades, starting in early childhood. There is no way to study a cohort in which the starting point is around that age.

\section{Discussion}

Despite the dietary differences in the countries and regions of the Mediterranean basin, fish, olive oil, and red wine occupy a central position in daily meals. Apart from the beneficial health effects of these components, they also facilitate the consumption of vegetables and legumes. This dietary pattern has been associated with a reduced risk of fatal and nonfatal cardiovascular disease [67, 68] and cancer [69]. In this context, it is worthwhile to mention the PREDIMED prospective study involving 19 groups from 7 regions in Spain. This study, begun in 2003 and presumably ending in 2011, monitors 7,232 people with cardiovascular risk receiving dietary and behavioral advice [70].

A recent meta-analysis by Sofi et al. [71] demonstrated that the Mediterranean diet is associated with a significant improvement in health status marked by a remarkable reduction in mortality due to CVD (9\%), incidence of and mortality from cancer (6\%), overall mortality (9\%), and incidence of Parkinson's and Alzheimer's diseases (13\%) [71]. These numbers are relevant for public health. It is interesting to note that in the above mentioned meta-analysis, 6 of the 8 cohort studies focused on Greek populations. A recent study by Trichopoulou et al. [72] on the Greek segment of EPIC, involving 23,349 men and women recruited throughout the country from the general population not previously diagnosed with cancer, provides evidence that after a follow-up of 8.5 years (range 10 days to 14.2 years) a higher adherence to the Mediterranean diet was associated with a statistically significant reduction in total mortality (adjusted mortality $0.86 ; 95 \%$ CI $0.80-0.93$ ). The contribution of the various components has been summarized as follows: moderate alcohol consumption (23\%), a low consumption of meat and meat products (16.6\%), high vegetable consumption (16.2\%), high fruit and nut consumption (11.2\%), a high ratio of monounsaturated to saturated lipids (10.6\%), and high legume consumption (9.7\%). The components relating to dairy products, cereals, and, surprisingly, fish and seafood were largely inconsequential and contributed little to predicting mortality. In this respect, Simopoulos [73] previously emphasized that the 
Cretan diet with its 'high intake of fruits and fruit juice, vegetables, herbs and spices, nuts (notably walnuts), garlic, onions, cereals (whole-wheat and sourdough rather than pasta), olive oil and olives, less milk, more goat cheese, less meat, more fish, yogurt, water and moderate amounts of red wine with meals' differs considerably from the diet that has been positively associated with cancer in Europe [74].

With regard to the relationship between wine and cardiovascular health, wine drinkers appear to have a healthier lifestyle than those who consume beer, spirits, or mixed drinks [75]. Wine drinkers are less likely to smoke and are more likely to have a lower body mass index and adhere to the Mediterranean diet [76]. The latter contributes to a relatively higher dietary level of omega- 3 fatty acids. In addition to their anticancer effects, these PUFAs contribute to a beneficial cardiac health effect via a reduced synthesis and secretion of very-low-density lipo- protein particles, increased triglyceride removal from these and chylomicron particles, and the upregulation of enzymes such as lipoprotein lipase [77].

\section{Conclusion}

The ideal study on the effect of the Mediterranean diet on health would be a long-term, prospective, doubleblind, randomized study of sufficient power. In the absence of such a study, there is still well-documented evidence of the beneficial effects of the diet consistent with an increased understanding of the mechanisms by which components of this diet act in an integrated manner within a matrix of molecules to mitigate risk factors. Recognition of its benefits may well lead to the Mediterranean diet becoming an indispensible part of a healthy lifestyle [78, 79].

\section{References}

1 Benetou V, Trichopoulou A, Orfanos P, Naska A, Lagiou P, Boffetta P, Trichopoulos D, Greek EPIC cohort: Conformity to traditional Mediterranean diet and cancer incidence: the Greek EPIC cohort. Br J Cancer 2008;99: 191-195.

- 2 Keys A, Menotti A, Karvonen MJ, Aravanis C, Blackburn H, Buzina R, Djordjevic BS, Dontas AS, Fidanza F, Keys MH, et al: The diet and 15-year death rate in the Seven Countries Study. Am J Epidemiol 1986;124: 903-915.

-3 Cunnane SC: Problems with essential fatty acids: time for a new paradigm? Prog Lipid Res 2003;42:544-568.

4 Serhan CN: Systems approach to inflammation resolution: identification of novel antiinflammatory and pro-resolving mediators. J Thromb Haemost 2009; 7(suppl 1):44-48.

5 Allred CD, Talbert DR, Southard RC, Wang $\mathrm{X}$, Kilgore MW: PPARgammal as a molecular target of eicosapentaenoic acid in human colon cancer (HT-29) cells. J Nutr 2008; 138 : 250-256.

-6 Muralidhar B, Carpenter KL, Müller K, Skepper JN, Arends MJ: Potency of arachidonic acid in polyunsaturated fatty acid-induced death of human monocyte-macrophages: implications for atherosclerosis. Prostaglandins Leukot Essent Fatty Acids 2004;71:251-262.

$\checkmark 7$ Zhao G, Etherton TD, Martin KR, Vanden Heuvel JP, Gillies PJ, West SG, Kris-Etherton PM: Anti-inflammatory effects of polyunsaturated fatty acids in THP-1 cells. Biochem Biophys Res Commun 2005;336:909-917.
-8 Hering J, Garrean S, Dekoj TR, Razzak A, Saied A, Trevino J, Babcock TA, Espat NJ: Inhibition of proliferation by omega-3 fatty acids in chemoresistant pancreatic cancer cells. Ann Surg Oncol 2007;14:3620-3628.

-9 Schley PD, Brindley DN, Field CJ: (n-3) PUFA alter raft lipid composition and decrease epidermal growth factor receptor levels in lipid rafts of human breast cancer cells. J Nutr 2007;137:548-553.

10 Yao HT, Chang YW, Lan SJ, Chen CT, Hsu JT, Yeh TK: The inhibitory effect of polyunsaturated fatty acids on human CYP enzymes. Life Sci 2006;79:2432-2440.

- 11 Yaqoob P, Calder PC: Fatty acids and immune function: new insights into mechanisms. Br J Nutr 2007;98(suppl 1):S41-S45.

12 Kenar L, Karayilanoglu T, Aydin A, Serdar M, Kose S, Erbil MK: Protective effects of diets supplemented with omega-3 polyunsaturated fatty acids and calcium against colorectal tumor formation. Dig Dis Sci 2008; 53: 2177-2182.

13 Tripoli E, Giammanco M, Tabacchi G, Di Majo D, Giammanco S, La Guardia M: The phenolic compounds of olive oil: structure, biological activity and beneficial effects on human health. Nutr Res Rev 2005;18:98-112.

14 Lau AT, Wang Y, Chiu JF: Reactive oxygen species: current knowledge and applications in cancer research and therapeutic. J Cell Biochem 2008;104:657-667.
15 Biesalski HK: Polyphenols and inflammation: basic interactions. Curr Opin Clin Nutr Metab Care 2007;10:724-728.

16 Owen RW, Haubner R, Würtele G, Hull E, Spiegelhalder B, Bartsch H: Olives and olive oil in cancer prevention. Eur J Cancer Prev 2004;13:319-326.

17 Booyse FM, Pan W, Grenett HE, Parks DA, Darley-Usmar VM, Bradley KM, Tabengwa EM: Mechanism by which alcohol and wine polyphenols affect coronary heart disease risk. Ann Epidemiol 2007;17:S24-S31.

18 Sasaki S: Alcohol and its relation to all-cause and cardiovascular mortality. Acta Cardiol 2000;55:151-156.

19 Opie LH, Lecour S: The red wine hypothesis: from concepts to protective signalling molecules. Eur Heart J 2007;28:1683-1693.

20 Shankar S, Singh G, Srivastava RK: Chemoprevention by resveratrol: molecular mechanisms and therapeutic potential. Front Biosci 2007;12:4839-4854.

21 Corder R, Mullen W, Khan NQ, Marks SC, Wood EG, Carrier MJ, Crozier A: Oenology: red wine procyanidins and vascular health. Nature 2006;444:566.

22 van de Wiel A, van Golde PH, Hart HC: Blessings of the grape. Eur J Intern Med 2001; 12:484-489.

23 MacLean CH, Newberry SJ, Mojica WA, Khanna P, Issa AM, Suttorp MJ, Lim YW, Traina SB, Hilton L, Garland R, Morton SC: Effects of omega- 3 fatty acids on cancer risk: a systematic review. JAMA 2006;295:403415 . 
24 Kuriki K, Hirose K, Wakai K, Matsuo K, Ito 35 Wang J, John EM, Horn-Ross PL, Ingles SA: H, Suzuki T, Hiraki A, Saito T, Iwata H, Tatematsu M, Tajima K: Breast cancer risk and erythrocyte compositions of n-3 highly unsaturated fatty acids in Japanese. Int J Cancer 2007;121:377-385.

25 Shannon J, King IB, Moshofsky R, Lampe JW, Gao DL, Ray RM, Thomas DB: Erythrocyte fatty acids and breast cancer risk: a casecontrol study in Shanghai, China. Am J Clin Nutr 2007;85:1090-1097.

26 Kim J, Lim SY, Shin A, Sung MK, Ro J, Kang HS, Lee KS, Kim SW, Lee ES: Fatty fish and fish omega-3 fatty acid intakes decrease the breast cancer risk: a case-control study. BMC Cancer 2009;9:216.

27 Leitzmann MF, Stampfer MJ, Michaud DS, Augustsson K, Colditz GC, Willett WC, Giovannucci EL: Dietary intake of n-3 and n-6 fatty acids and the risk of prostate cancer. Am J Clin Nutr 2004;80:204-216.

-28 Virtanen JK, Mozaffarian D, Chiuve SE, Rimm EB: Fish consumption and risk of major chronic disease in men. Am J Clin Nutr 2008;88:1618-1625.

29 Domingo JL: Omega-3 fatty acids and the benefits of fish consumption: is all that glitters gold? Environ Int 2007;33:993-998.

30 Amin M, Jeyaganth S, Fahmy N, Bégin LR, Aronson S, Jacobson S, Tanguay S, Kassouf W, Aprikian A: Dietary habits and prostate cancer detection: a case-control study. Can Urol Assoc J 2008;2:510-515.

31 Ritch CR, Wan RL, Stephens LB, Taxy JB, Huo D, Gong EM, Zagaja GP, Brendler CB: Dietary fatty acids correlate with prostate cancer biopsy grade and volume in Jamaican men. J Urol 2007;177:97-101.

- 32 Norat T, Bingham S, Ferrari P, Slimani N, Jenab M, Mazuir M, Overvad K, Olsen A, Tjønneland A, Clavel F, Boutron-Ruault MC, Kesse E, Boeing H, Bergmann MM, Nieters A, Linseisen J, Trichopoulou A, Trichopoulos D, Tountas Y, Berrino F, Palli D, Panico $\mathrm{S}$, Tumino R, Vineis P, Bueno-de-Mesquita HB, Peeters PH, Engeset D, Lund E, Skeie G, Ardanaz E, González C, Navarro C, Quirós JR, Sanchez MJ, Berglund G, Mattisson I, Hallmans G, Palmqvist R, Day NE, Khaw KT, Key TJ, San Joaquin M, Hémon B, Saracci R, Kaaks R, Riboli E: Meat, fish, and colorectal cancer risk: the European Prospective Investigation into Cancer and $\mathrm{Nu}$ trition. J Natl Cancer Inst 2005;97:906-916.

-33 Hall MN, Chavarro JE, Lee IM, Willett WC, Ma J: A 22-year prospective study of fish, $n-3$ fatty acid intake, and colorectal cancer risk in men. Cancer Epidemiol Biomarkers Prev 2008;17:1136-1143.

- 34 Kuriki K, Wakai K, Hirose K, Matsuo K, Ito H, Suzuki T, Saito T, Kanemitsu Y, Hirai T, Kato T, Tatematsu M, Tajima K: Risk of colorectal cancer is linked to erythrocyte compositions of fatty acids as biomarkers for dietary intakes of fish, fat, and fatty acids. Cancer Epidemiol Biomarkers Prev 2006;15: 1791-1798.
Dietary fat, cooking fat, and breast cancer risk in a multiethnic population. Nutr Cancer 2008;60:492-504.

36 Schulz M, Hoffmann K, Weikert C, Nöthlings $\mathrm{U}$, Schulze MB, Boeing H: Identification of a dietary pattern characterized by high-fat food choices associated with increased risk of breast cancer: the European Prospective Investigation into Cancer and Nutrition (EPIC)-Potsdam Study. Br J Nutr 2008;101:942-946.

37 Chajès V, Thiébaut AC, Rotival M, Gauthier E, Maillard V, Boutron-Ruault MC, Joulin V, Lenoir GM, Clavel-Chapelon F: Association between serum trans-monounsaturated fatty acids and breast cancer risk in the $\mathrm{E} 3 \mathrm{~N}$ EPIC Study. Am J Epidemiol 2008; 167:13121320.

- 38 Sieri S, Krogh V, Ferrari P, Berrino F, Pala V, Thiébaut AC, Tjønneland A, Olsen A, OverChajes V, Boutron-Ruault MC, Kaaks R, Linseisen J, Boeing H, Nöthlings U, Trichopoulou A, Naska A, Lagiou P, Panico S, Palli D, Vineis P, Tumino R, Lund E, Kumle M, Skeie G, González CA, Ardanaz E, Amiano P, Tormo MJ, Martínez-García C, Quirós JR, Berglund G, Gullberg B, Hallmans G, Lenner P, Bueno-de-Mesquita HB, van Duijnhoven FJ, Peeters PH, van Gils CH, Key TJ, Crowe FL, Bingham S, Khaw KT, Rinaldi S, Slimani N, Jenab M, Norat T, Riboli E: Dietary fat and breast cancer risk in the European Prospective Investigation into Cancer and Nutrition. Am J Clin Nutr 2008;88:1304-1312.

39 Fitó M, de la Torre R, Covas MI: Olive oil and oxidative stress. Mol Nutr Food Res 2007;51: 1215-1224.

40 Machowetz A, Poulsen HE, Gruendel S, Weimann A, Fitó M, Marrugat J, de la Torre R, Salonen JT, Nyyssönen K, Mursu J, Nascetti S, Gaddi A, Kiesewetter H, Bäumler H, Selmi H, Kaikkonen J, Zunft HJ, Covas MI, Koebnick C: Effect of olive oils on biomarkers of oxidative DNA stress in Northern and Southern Europeans. FASEB J 2007;21:4552.

41 Crowe FL, Key TJ, Appleby PN, Travis RC, Overvad K, Jakobsen MU, Johnsen NF, Tjønneland A, Linseisen J, Rohrmann S, Boeing H, Pischon T, Trichopoulou A, Lagiou P, Trichopoulos D, Sacerdote C, Palli D, Tumino $\mathrm{R}$, Krogh V, Bueno-de-Mesquita HB, Kiemeney LA, Chirlaque MD, Ardanaz E, Sánchez MJ, Larrañaga N, González CA, Quirós JR, Manjer J, Wirfält E, Stattin P, Hallmans G, Khaw KT, Bingham S, Ferrari P, Slimani N, Jenab M, Riboli E: Dietary fat intake and risk of prostate cancer in the European Prospective Investigation into Cancer and Nutrition. Am J Clin Nutr 2008;87: 1405-1413.

42 Park SY, Murphy SP, Wilkens LR, Henderson $\mathrm{BE}$, Kolonel LN: Fat and meat intake and prostate cancer risk: the multiethnic cohort study. Int J Cancer 2007;121:1339-1345. vad K, Jakobsen MU, Clavel-Chapelon F,
43 Theodoratou E, McNeill G, Cetnarskyj R, Farrington SM, Tenesa A, Barnetson R, Porteous M, Dunlop M, Campbell H: Dietary fatty acids and colorectal cancer: a case-control study. Am J Epidemiol 2007; 166:181195.

44 Stoneham M, Goldacre M, Seagroatt V, Gill L: Olive oil, diet and colorectal cancer: an ecological study and a hypothesis. J Epidemiol Community Health 2000;54:756-760.

45 Cicerale S, Conlan XA, Sinclair AJ, Keast RS: Chemistry and health of olive oil phenolics. Crit Rev Food Sci Nutr 2009;49:218-236.

46 St Leger AS, Cochrane AL, Moore F: Factors associated with cardiac mortality in developed countries with particular reference to the consumption of wine. Lancet 1979;1: 1017-1020.

47 Renaud S, de Lorgeril M: Wine, alcohol, platelets, and the French paradox for coronary heart disease. Lancet 1992;339:15231526.

-48 Di Castelnuovo A, Costanzo S, Bagnardi V, Donati MB, Iacoviello L, de Gaetano G: Alcohol dosing and total mortality in men and women: an updated meta-analysis of 34 prospective studies. Arch Intern Med 2006;166: 2437-2445.

49 Gaziano JM, Gaziano TA, Glynn RJ, Sesso HD, Ajani UA, Stampfer MJ, Manson JE, Hennekens CH, Buring JE: Light-to-moderate alcohol consumption and mortality in the Physicians' Health Study enrollment cohort. J Am Coll Cardiol 2000;35:96-105.

50 Klatsky AL, Armstrong MA, Friedman GD: Alcohol and mortality. Ann Intern Med 1992;117:646-654.

-51 Snow WM, Murray R, Ekuma O, Tyas SL, Barnes GE: Alcohol use and cardiovascular health outcomes: a comparison across age and gender in the Winnipeg Health and Drinking Survey Cohort. Age Ageing 2009; 38:206-212.

52 Bazzano LA, Gu D, Reynolds K, Chen J, Wu X, Chen CS, Duan X, Chen J, He J: Alcohol consumption and risk of coronary heart disease among Chinese men. Int J Cardiol 2009; 135:78-85.

53 Saremi A, Arora R: The cardiovascular implications of alcohol and red wine. Am J Ther 2008; 15:265-277.

-54 Foerster M, Marques-Vidal P, Gmel G, Daeppen JB, Cornuz J, Hayoz D, Pécoud A, Mooser V, Waeber G, Vollenweider P, Paccaud F, Rodondi N: Alcohol drinking and cardiovascular risk in a population with high mean alcohol consumption. Am J Cardiol 2009; 103: 361-368

55 Grønbaek M, Becker U, Johansen D, Gottschau A, Schnohr P, Hein HO, Jensen G, Sørensen TI: Type of alcohol consumed and mortality from all causes, coronary heart disease, and cancer. Ann Intern Med 2000; 133:411-419. 
56 Renaud SC, Guéguen R, Conard P, Lanzmann-Petithory D, Orgogozo JM, Henry O: Moderate wine drinkers have lower hypertension-related mortality: a prospective cohort study in French men. Am J Clin Nutr 2004;80:621-625.

- 57 Klatsky AL, Friedman GD, Armstrong MA, Kipp H: Wine, liquor, beer, and mortality. Am J Epidemiol 2003;158:585-595.

58 Karatzi K, Papamichael C, Aznaouridis K, Karatzis E, Lekakis J, Matsouka C, Boskou G, Chiou A, Sitara M, Feliou G, Kontoyiannis D, Zampelas A, Mavrikakis M: Constituents of red wine other than alcohol improve endothelial function in patients with coronary artery disease. Coron Artery Dis 2004; 15:485-490.

59 Agewall S, Wright S, Doughty RN, Whalley GA, Duxbury M, Sharpe N: Does a glass of red wine improve endothelial function? Eur Heart J 2000;21:74-78.

-60 Karatzi K, Papamichael C, Karatzis E, Papaioannou TG, Voidonikola PT, Lekakis J, Zampelas A: Acute smoking induces endothelial dysfunction in healthy smokers: is this reversible by red wine's antioxidant constituents? J Am Coll Nutr 2007;26:10-15.

61 Kiviniemi TO, Saraste A, Lehtimäki T, Toikka JO, Saraste M, Raitakari OT, Hartiala JJ, Viikari J, Koskenvuo JW: Decreased endothelin-1 levels after acute consumption of red wine and de-alcoholized red wine. Atherosclerosis 2010;211:283-286.

62 Opie LH, Lecour S: The red wine hypothesis: from concepts to protective signalling molecules. Eur Heart J 2007;28:1683-1693.
63 Mukamal KJ, Conigrave KM, Mittleman MA, Camargo CA Jr, Stampfer MJ, Willett WC, Rimm EB: Roles of drinking pattern and type of alcohol consumed in coronary heart disease in men. N Engl J Med 2003;348: 109-118.

64 van de Wiel A, de Lange DW: Cardiovascular risk is more related to drinking pattern than to the type of alcoholic drinks. Neth J Med 2008;66:467-473.

65 Dudley JI, Lekli I, Mukherjee S, Das M, Bertelli AA, Das DK: Does white wine qualify for French paradox? Comparison of the cardioprotective effects of red and white wines and their constituents: resveratrol, tyrosol, and hydroxytyrosol. J Agric Food Chem 2008;56:9362-9373.

66 Zamora-Ros R, Urpí-Sardà M, LamuelaRaventós RM, Estruch R, Martínez-González MA, Bulló M, Arós F, Cherubini A, Andres-Lacueva C: Resveratrol metabolites in urine as a biomarker of wine intake in freeliving subjects: the PREDIMED Study. Free Radic Biol Med 2009;46:1562-1566.

67 Lairon D: Intervention studies on Mediterranean diet and cardiovascular risk. Mol Nutr Food Res 2007;51:1209-1124.

68 Martínez-González MA, García-López M, Bes-Rastrollo M, Toledo E, Martínez-Lapiscina EH, Delgado-Rodriguez M, Vazquez Z, Benito S, Beunza JJ: Mediterranean diet and the incidence of cardiovascular disease: a Spanish cohort. Nutr Metab Cardiovasc Dis 2010, E-pub ahead of print.

69 Bosetti C, Pelucchi C, La Vecchia C: Diet and cancer in Mediterranean countries: carbohydrates and fats. Public Health Nutr 2009; 12:1595-1600.

-70 Martinez-Gonzalez MA, Bes-Rastrollo M, Serra-Majem L, Lairon D, Estruch R, Trichopoulou A: Mediterranean food pattern and the primary prevention of chronic disease: recent developments. Nutr Rev 2009;67 (suppl 1):S111-S116.
71 Sofi F, Cesari F, Abbate R, Gensini GF, Casini A: Adherence to Mediterranean diet and health status: meta-analysis. BMJ 2008; 337:a1344.

72 Trichopoulou A, Bamia C, Trichopoulos D: Anatomy of health effects of Mediterranean diet: Greek EPIC prospective cohort study. BMJ 2009;338:b2337.

73 Simopoulos AP: The Mediterranean diets: what is so special about the diet of Greece? The scientific evidence. J Nutr 2001;131: 3065S-3073S.

74 Kapiszewska M: A vegetable to meat consumption ratio as a relevant factor determining cancer preventive diet: the Mediterranean versus other European countries. Forum Nutr 2006;59:130-153.

75 Ruidavets JB, Bataille V, Dallongeville J, Simon C, Bingham A, Amouyel P, Arveiler D, Ducimetière $\mathrm{P}$, Ferrières J: Alcohol intake and diet in France, the prominent role of lifestyle. Eur Heart J. 2004;25:1153-1162.

76 Barefoot JC, Grønbaek M, Feaganes JR, McPherson RS, Williams RB, Siegler IC: Alcoholic beverage preference, diet, and health habits in the UNC Alumni Heart Study. Am J Clin Nutr 2002;76:466-472.

77 Bays HE, Tighe AP, Sadovsky R, Davidson $\mathrm{MH}$ : Prescription omega-3 fatty acids and their lipid effects: physiologic mechanisms of action and clinical implications. Expert Rev Cardiovasc Ther 2008;6:391-409.

$\checkmark 78$ La Vecchia C: Mediterranean diet and cancer. Public Health Nutr 2004;7:965-968.

-79 Escrich E, Moral R, Grau L, Costa I, Solanas M: Molecular mechanisms of the effects of olive oil and other dietary lipids on cancer. Mol Nutr Food Res 2007;51:1279-1292. 